Julian Everett Allgood (everett.allgood @nyu.edu) is Serials Cataloger, Technical Services Department, New York University Libraries, New York, New York.

An article like this is never completed without help from others. Christina Bellinger of the LRTS Editorial Board was instrumental in helping me wrestle the article into a manageable size. Others who have provided invaluable assistance during various stages include: John Attig, Matthew Beacom, Bea Caraway, Sherman Clarke, Karen Coyle, Carol Hutchins, Bill Jones, Ed Jones, Arno Kastner, Sara Shatford Layne, David Levin, Elizabeth Lilker, Tom McNulty, and Martha Yee. All errors, discrepancies, or misinterpretations are solely my own. I also thank my wife, Judith. Without her patience, understanding, and support I could never have completed this project. My children, Theo and Esme, also showed amazing reservoirs of patience and understanding for two so young

Submitted November 23, 2005; returned to author for revision and resubmission; resubmitted July 28, 2006; accepted for publication October 9, 2006, pending revision; revision submitted December 22,2006 , and accepted for publication.

\section{Serials and Multiple Versions, or the Inexorable Trend toward Work-Level Displays}

\section{By Julian Everett Allgood}

The proliferation of multiple versions for bibliographic works presents numerous challenges to the cataloger and, by extension, to the catalog user. Fifteen years after the Multiple Versions Forum held in Airlie, Virginia, online public access catalog (OPAC) users continue to grapple with confusing displays representing numerous serial manifestations (i.e., versions) resulting from the Anglo-American Cataloguing Rules' (AACR2) cardinal principle (Rule 0.24). Two initiatives offer hope for more coherent OPAC displays in light of a renewed focus upon user needs: the ongoing revision of AACR2, and the International Federation of Library Associations and Institutions' Functional Requirements for Bibliographic Records (FRBR) model. A third potential tool for improving OPAC displays exists within a series of standards that have developed to parallel library needs, and today offer a robust communications medium: the MARC 21 authority, bibliographic, and holdings formats. This paper summarizes the challenges posed by multiple versions and presents an analysis of current and emerging solutions.

A dilemma confronts the Anglo-American cataloging community. Library Acatalogs display multiple occurrences of titles available in different formats as multiple hits for a user's search query, rather than clustering them into a single entry or hit. The variety of formats and versions of resources libraries collect continues to grow, yet the underlying manifestation level principles of the AngloAmerican Cataloguing Rules, 2nd ed. (AACR2) result in catalogs difficult for users to navigate. ${ }^{1}$ This multiple versions (MulVer) problem represents a defining challenge of the automated catalog era.

This paper will examine the MulVer problem with regard to serial resources and will consider both the Joint Steering Committee for Revision of AngloAmerican Cataloguing Rules (JSC) mandate to revise AACR2 and the growing influence of the Functional Requirements for Bibliographic Records (FRBR) model. ${ }^{2}$ As my conclusions are aimed at current and developing solutions to the MulVer problem, the literature I cite was written largely within the last fifteen years. The paper calls for online public access catalog (OPAC) displays allowing users to more easily understand and navigate the rich, complex collections librarians assemble.

Unless otherwise noted, the term "users" refers to external library users rather than to library staff members. For library staff members or internal library users, manifestation-level detail is necessary for ordering, record identification, 
check-in, and other library functions. That a given data element serves a purpose for internal library staff, however, does not necessitate its display to all library users. Much of the manifestation-level detail of AACR2 serial bibliographic records currently displayed in library OPACs is inconsequential for external library users. Users are more interested in obtaining the journal article content than in the manifestation-level details of the serial title in which the article is published. As indicated by Lubetzky, researchers typically approach the library OPAC with a citation to a specific issue of a specific volume of a specific serial work. ${ }^{3}$ They simply need to know if the collection contains the serial title and issue containing the selected article. Library catalogs following AACR2 Rule 0.24 contain a separate OPAC record for each version or manifestation of each serial work or expression. For serial titles that many library catalogs contain in multiple physical formats, these separate OPAC records for equivalent versions further increase the likelihood for user confusion.

Antelman has illustrated that the core responsibility of librarians and library catalogs remains to guide users to the content they seek. ${ }^{4}$ In the case of serial resources, users seek content at the article level more often than at the title or physical manifestation level. Thus the first obstacle users must overcome in order to identify, select, and obtain serial resources within library catalogs is that librarians long ago abdicated the role of providing article-level journal citations to abstracting and indexing agencies. Library catalogs typically provide title-level access to their journal collections. It is left to others to provide users with citations to the wealth of content within each of these serial titles. In addition to providing access to journal titles, library catalogs have historically done an admirable job of informing users of the various formats or versions serials are issued in, and the means for using them. For example, the full serial run of The New Yorker on CD-ROM would be of little use without access to a computer able to display the disc contents. Today's users prefer that everything be available online, but they still routinely use articles on paper or microform. Again, users simply want to know if the library has the journal content (i.e., article) they need. They are confused and frustrated by library catalogs forcing them to examine separate records for each format or manifestation. Based on how users struggle with serial multiple versions, today's librarians and library catalogs are not fulfilling the core responsibility of guiding users to content.

\section{Rule 0.24 and Manifestation-Level Cataloging in AACR2}

AACR2, the International Standard Bibliographic Descriptions (ISBDS) and the International Standard Serial
Number (ISSN) Manual are presently undergoing significant revision with emphasis upon addressing user needs. ${ }^{5}$ This therefore seems an ideal time to reconsider some of the underlying precepts and principles of cataloging.

The cardinal principle of AACR2 Rule 0.24 is the foundation for manifestation-level cataloging, which results in record displays that confuse and frustrate users. From AACR2's initial publication in 1978 until 2002, Rule 0.24 read (with minor wording changes):

It is a cardinal principle of the use of part I that the description of a physical item should be based in the first instance on the chapter dealing with the class of materials to which that item belongs. . . . In short, the starting point for description is the physical form of the item in hand, not the original or any previous form in which the work has been published. ${ }^{6}$

Many believe this focus upon the physical carrier expressed in Rule 0.24 has resulted in the MulVer problem. ${ }^{7}$ For example, Graham concludes, "the logical extension of this cardinal principle is the prescription to create a unique record for almost every variant manifestation of a work." Others are convinced that nowhere in AACR2, neither in Rule 0.24 nor anywhere else, does the code mandate that catalogers build a separate descriptive record. Attig has written, "This rule does not tell [catalogers] whether or not they must describe each manifestation."

The 2002 AACR2 rule revision significantly changed Rule 0.24 for the first time. This revision was in response to the Committee on Cataloging: Description and Access (CC:DA) Task Force on Rule 0.24 recommendations, and as Beacom points out, represents a "solid improvement." current Rule 0.24 reads:

It is important to bring out all aspects of the item being described, including its content, its carrier, its type of publication, its bibliographic relationships, and whether it is published or unpublished. In any given area of the description, all relevant aspects should be described. As a rule of thumb, the cataloger should follow the more specific rules applying to the item being cataloged, whenever they differ from general rules. ${ }^{11}$

Despite revision, it is difficult not to read this rule as an instruction to continue cataloging physical carriers. The phrase "item being described/item being cataloged" appears twice, and "carrier information" is second in the list of enumerated attributes. Carrier information is not unimportant; yet according to user studies it is not the most important manifestation-level attribute to be described. 
Manifestation-level cataloging has become the default norm within AACR2 cataloging for two reasons. The first centers upon cooperative cataloging. In a cooperative cataloging environment in which individual libraries exchange surrogate descriptions to facilitate and enhance user access to their collections of manifestations, describing those shared surrogates at the manifestation level is logical. Within today's shared cataloging environment in which millions of records are available to libraries through bibliographic utilities such as OCLC and RLIN, it is critical that cataloging and acquisitions librarians be able to select specific manifestations to import into their library catalogs. Describing resources at the manifestation level enables library personnel to do so. The second reason for using manifestationlevel records is that libraries need bibliographic records to serve duties beyond their most visible role as surrogate descriptions within the OPAC. Many of the administrative functions librarians perform such as ordering, check-in, and claiming are manifestation specific. Librarians need today's integrated library management systems (ILMS) to utilize records serving both purposes. Software designers developing ILMS systems must understand this duality of purpose.

\section{Departures from Manifestation-Level Cataloging within Current AACR2 Practice}

As Howarth points out, "While the cataloguing code is explicit in its directives for handling different manifestations of the same title or work, application of those rules has been less than consistent." 12 For example, Chapter 11 of AACR2 describes manifestation-level cataloging for microform resources. However, a Library of Congress Rule Interpretation (LCRI) for Chapter 11 instructs catalogers to base their descriptions on the original resource rather than the microform in hand. ${ }^{13}$ Most American libraries follow the rule interpretation rather than AACR2. Those libraries that follow the LCRI in effect clone the manifestation level record for the original, and add a note describing the microform holdings. For those libraries with holdings of both the original resource and the microform reproduction, as is often the case with serial resources, this creates a cluster of virtually identical, separate records for the title that users must then view one at a time. This is frustrating. This deviation from strict manifestation-based cataloging results in confusing records within OPACs and conflicting records within the internationally shared bibliographic utilities.

Two current Cooperative Online Serials Program (CONSER) practices also deviate from manifestation-level cataloging in favor of a more pragmatic, user-oriented approach. The first is CONSER's single-record approach. ${ }^{14}$ During the 1990s, many serials catalogers balked at the prospect of adding yet another bibliographic record for yet another equivalent online version to their local OPACs to remain in accord with national policy and AACR2 Rule 0.24.
In response, CONSER developed an alternate approach, allowing catalogers to append descriptive and access attributes for online manifestations to existing print descriptions. In theory, this represented a clear, practical solution to a pressing problem. This technique of providing access to two separate manifestations upon a single bibliographic description led to worries about how ILMS systems would continue the double duty of OPAC display and administrative functionality. Having responded to earlier requests to recognize and handle distributed, consortial library structures and to adhere to the MARC 21 Holdings standard, ILMS systems provided a technique for libraries to attach multiple holdings records along with the individual check-in and receiving attributes necessary to coordinate these separate manifestations or versions. ILMS software designers had therefore cleared a significant hurdle of the MulVer problem.

The practical implications for libraries willing to extrapolate from CONSER's single-record guidelines were immense. Citing the precedent set by guidelines of the United States Newspaper Project, and in response to a clear user preference and need, some libraries began to bundle all equivalent serial manifestations upon a single bibliographic description. ${ }^{15}$ This requires selecting one manifestation to serve as a serial work description or springboard with all equivalent manifestations attached as a holdings record. While attaching and displaying multiple manifestations to a single bibliographic description within some ILMS systems is both possible and practical, sharing or exchanging manifestation and holdings information across our cooperative, distributed cataloging environment is difficult.

The second current CONSER practice that strays from manifestation-level cataloging is the aggregator-neutral record. ${ }^{16}$ Approved in 2003, aggregator-neutral records reflect the reality that not only are more serial titles available online, many of these online journals are simultaneously available from more than one provider or aggregator. The aggregator-neutral record allows catalogers to create a single bibliographic description representing an online serial and then attach as many access paths or URLs as necessary. When providers subsequently add or remove titles from their packages of electronic journals, catalogers simply add or remove the corresponding URL rather than having to create or delete entire bibliographic descriptions. Figure 1 is an example of a CONSER aggregator-neutral serial record. This particular title is available online from Project Muse, JSTOR, and Ingenta, among others.

Despite the benefit to users, sharing these records within a cooperative cataloging environment is difficult. By providing access to multiple serial manifestations, these bibliographic records come dangerously close to compromising the integrity of the MARC 21 standard as applied within the AACR2 environment. In the single-record approach, descriptions of print and online manifestations of a serial include an 856 field (used for electronic access and location 
information) and, until recently, an optional 007 field (physical characteristics) describing the specific material designation of the online manifestation. At the 2005 CONSER Operations Committee Meeting, it was determined that including the 007 field in records using the single-record technique causes confusion for the ISSN Centers and other user communities. Therefore, CONSER will write and present a discussion paper to the American Library Association's (ALA) Machine-Readable Bibliographic Information (MARBI) Committee proposing a one-byte "electronic online resource" value for the $008 / 23$ byte ${ }^{17}$ Confusion for some user communities arises because the majority of the record describes the print manifestation. Only by reading and understanding a 530 note (additional physical formats available) detailing the availability of an online version will users comprehend why a record describing the 007 and 856 fields are included upon what otherwise appears to be a print description. Furthermore, this bundling of multiple serial manifestations on a single bibliographic record complicates the batch processing capabilities of automated systems.

These two CONSER practices are admirable in attempting to provide a means of displaying equivalent serial versions to facilitate the needs of users. Within today's MARC 21 and AACR2 environment, these two CONSER practices create problems for users and the automated systems upon which libraries rely. Librarians and ILMS systems designers need to consider user preferences in providing access to serial resources. If librarians decide to modify the descriptive preferences and access guidelines for serial resources within the revised cataloging code and also modify the MARC 21 communications formats libraries use for exchanging records, the immediate results may include enhanced record sharing and display capabilities. When the JSC circulated the AACR3 draft of Part 1 for comments in early 2005, one prominent concern raised in the ALA response was that the draft failed to address either the MulVer problem or the single-record approach many libraries use to minimize its effects. ${ }^{18}$

Just as AACR2 Rule 0.24 is sometimes interpreted as not mandating manifestation-level cataloging, it may similarly be read as not requiring cohesive manifestation-level displays. The important principle within Rule 0.24 is that catalogers portray specific manifestation-level attributes. Only through doing so can catalogs and OPACs achieve Cutter's third objective of describing for users all available editions/versions/manifestations of a work. ${ }^{19}$ How these manifestation-level attributes are best communicated and displayed to users through the MARC 21 authority, bibliographic, and holdings formats is a decision best left to catalogers and catalog designers. Having demonstrated that departures from manifestation-level cataloging exist today, we need to look more closely at the MulVer problem.

\section{The MulVer Dilemma-Development and Recognition of the Multiple Versions Problem}

By the early 1980s, libraries recognized what is now known as the Multiple Versions, or MulVer, problem (also sometimes referred to as the format variation problem). In 1989, Graham wrote a seminal paper addressing the reasons for its emergence and identifying the problems MulVer has wrought upon catalogs. ${ }^{20}$ Some argue that the MulVer problem stems primarily from strict adherence to the cardinal principle of AACR2 (Rule 0.24). Additional factors have contributed, as well. Mandel indicates that technological advances within the publishing industry and especially electronic publishing, coupled with the preservation reproductions commissioned by libraries, have contributed to numerous versions of many works. ${ }^{21}$ In today's era of digital manifestations, the MulVer problem has only increased. Weiss states, "Since electronic data can be republished at almost no cost, multiple versions,

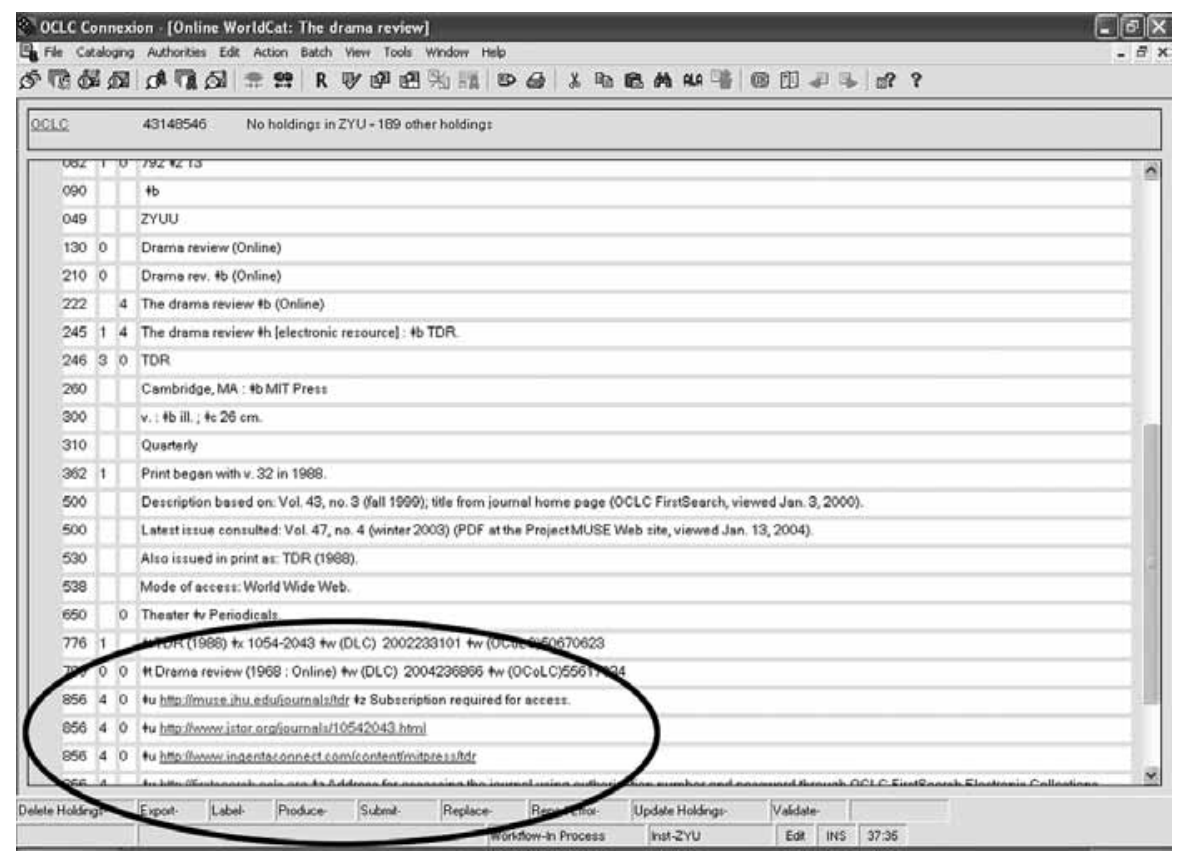

Figure 1. CONSER aggregator-neutral serial record available via multiple online providers 
many with only minor changes from the previous version, are [today] the rule rather than the exception." ${ }^{22}$ As early as 1989, the MulVer problem had grown to such an extent that a meeting of experts was convened by the Library of Congress and the Council on Library Resources at the encouragement of the CONSER Policy Committee. ${ }^{23}$ The Multiple Versions Forum was held December 5-8, 1989, in Airlie, Virginia.

Participants at the forum considered four distinct proposals for addressing the MulVer problem:

1. A composite, or single-record approach;

2. A two-tier hierarchical model;

3. A three-tier hierarchical model; and

4. A separate record model.

Each technique was evaluated based on a specific set of criteria including, but not limited to, clarity and ease of access for end users, ability to create and maintain records, ability to implement the proposed technique within the existing hardware and software environment, and cost effectiveness. Forum participants recommended the two-tier hierarchical model, in which "equivalent versions" should be attached to a single bibliographic record in the OPAC. The bibliographic record should describe only the "original" version. ${ }^{24}$ To this bibliographic record are appended MARC Holdings records, each describing the physical version of the attached items.

In retrospect, the 1989 Airlie Multiple Versions Forum had little lasting effect. ${ }^{25}$ Howarth notes that while the report was widely known and cited, its recommendations were never implemented. Multiple versions remained a problem within the automated environment mainly because in 1989 library automation vendors were not equipped to pursue the Airlie recommendations. ${ }^{26}$

During the early 1990s, ALA's CC:DA continued to grapple with the MulVer problem by assembling a Multiple Versions Task Force. In reference to calls for abandoning AACR2's cardinal principle, Attig, one of the group's members, noted the major obstacle of reconfiguring both bibliographic databases and user interfaces to accommodate two-tier records. Attig wisely cited not only the infrastructural need of systems to support these records as libraries move ever onward, but also the need to somehow reconfigure the millions of existing records in library catalogs to function properly within this new world order. ${ }^{27}$ Attig concluded, "It is my feeling that it would be a mistake to abandon [Rule] 0.24 . . . I think that it would be a mistake for catalogers to get into the business of textual scholars." ${ }^{\text {"2s }}$ On the other hand, librarians do have the responsibility to develop userfriendly mechanisms for grouping displays for the related works, expressions, and manifestations that textual scholars may identify and select to study —in other words, to ensure that catalogs fulfill Cutter's second objective.
The MulVer problem persisted throughout the 1990s, and in 1999 CC:DA assembled the Task Force on Rule 0.24, which revised Rule 0.24 to lessen its emphasis upon the physical carrier. ${ }^{29}$ In so doing, the Task Force was certainly aware of the precedent set by the recently revised and republished International Standard Bibliographic Description, Electronic Resources (ISBD [ER]) of $1997 .^{30}$ Therein, Weiss writes that for the first time, an international standard allows:

The inclusion of all physical forms of the content on the same bibliographic record [thereby enabling] the record to focus on the content of the work. The physical forms of the work become subordinate instances of the intellectual work, which clearly shows the influence of research done on bibliographic relationships by Barbara Tillett and others (including the International Federation of Library Associations and Institutions (IFLA) Study Group on the Functional Requirements of the Bibliographic Record). In this case, works that have what Tillett refers to as "equivalence relationships," e.g., works where the authorship and intellectual content are identical, were grouped together on a single record. Conceptually, this was a shift from AACR2 1988 (with its emphasis on specific item description) to the notion that the physical carrier of the information was of only incidental interest to users, who first and foremost would want access to information in whatever form it was available [emphasis added]. ${ }^{31}$

What exact role AACR2 Rule 0.24 may eventually play in the new cataloging code, Resource Description and Access $(R D A)$ is unknown. The CC:DA Task Force on Rule 0.24 Final Report has called upon the JSC to add an introductory chapter to the cataloging code that specifically will address a number of big picture topics, including the format variation or MulVer issue. ${ }^{32}$ In response, the JSC assembled the Format Variation Working Group (FVWG), and charged it with exploring expression-level cataloging. After realizing how few definable and transcribable attributes exist for the expression level, the FVWG group shifted focus to expression-level collocation, or bringing together all disparate manifestations of a particular expression within a catalog. This led to an exploration of uniform title authority records as a means of distinguishing specific works and expressions within catalogs and of collocating manifestations of the same work and expression. ${ }^{33}$ The emphasis moved from the records themselves to the display of the records. ${ }^{34}$ This transition itself represents a FRBR influence, as the group went from focusing upon the minutiae of individual catalog records to considering the larger issue of catalogs and displays. 
Based on the abilities of today's library catalogs, the continuing development of the MARC 21 communications standards, further advances in technology and computing, and increasingly sophisticated users, libraries need to reexamine the MulVer problem and the AACR2 principle from which it arises. First, the automation environment in which libraries and information professionals operate today is almost completely different from what it was at the time of the Multiple Versions Forum recommendations in 1989. Today most large libraries have fully automated their processing and have migrated to a second-generation ILMS available from one of only a handful of library automation vendors. This consolidated automation environment facilitates not only the recognition of new functionality and usage models such as FRBR, but also the implementation of innovations considered beneficial to the shared mission and cooperative efforts of libraries around the world.

Second, as the international library automation marketplace has consolidated, libraries and users have benefited from developing standards, harmonization efforts, and cooperative cataloging. Today, the MARC 21 Format for Holdings Data has matured into a robust carrier fully supportive of significant descriptive and encoded information. ${ }^{35}$ The development of the MARC 21 standards and a general move away from local processing eccentricities has provided cost efficiencies for library budgets. Meanwhile users have benefited from harmonized OPAC result displays. Each of these initiatives has been furthered by enhanced cooperative cataloging efforts.

Third, the Internet and wireless technology have fundamentally transformed the manner in which users access information and conduct research. Howarth has demonstrated that continuing development since the 1989 Multiple Versions Forum has resulted in a generation of catalogs capable of displaying individual records featuring dynamic linking fields able to link across records and across databases. ${ }^{36}$

Finally, users today have no patience for confusing OPAC displays with multiple hits for equivalent resources. Antelman points out, "In order to make our bibliographic data valuable to scholars and others who seek [serial] works, asserting bibliographic control over a higher level of abstraction than has been our practice is necessary." ${ }^{\text {"37 }}$ Marcum of the Library of Congress goes further in admitting, "the detailed attention that we have been paying to descriptive cataloging may no longer be justified." ${ }^{, 38}$ Howarth and others see a need for bibliographic records or displays that present all manifestations of a work, making the carriers of the manifestations secondary ${ }^{39}$ Resolving the MulVer problem is in libraries' vital interest as we endeavor to redefine the Anglo-American Cataloguing Rules for a new generation of users.

\section{Resolving Multiple Versions}

In confronting the MulVer problem today, librarians have two viable options: change cataloging practices or improve OPAC displays. Yee has recently argued that many of the problems multiple versions present for users could be resolved if catalogers "were allowed [by the cataloging code] to use the MARC 21 holdings format to attach more than one manifestation to a single bibliographic record." ${ }^{.40}$ Such an OPAC could then be optimized by providing a "welldesigned holdings display [allowing users to sort] holdings by format, by location, by reproduction date, and so on." Efforts to revise AACR2 are currently underway with a new cataloging code for the Anglo-American community expected in 2009. Within the current cooperative cataloging environment, a cataloging code advocating anything other than manifestation-level descriptions appears unlikely. With millions of existing manifestation-level descriptions populating our catalogs and with a great deal of internal library functionality dependent upon specific manifestations, libraries need to continue to create and have access to manifestation-level descriptions.

This brings us to our second option. OPAC displays have developed far too little since libraries began automating their card catalogs during the 1960s. In spite of today's hyperlinked, graphics-oriented, Web-based environment, most library OPACs continue to display descriptions as distinct records, little more than an electronic card catalog. ${ }^{42}$ Recent offerings such as hot-linked fields and operational URLs appear paltry compared to the technological wizardry available today. ILMS systems designers and developers need to acknowledge that though library systems need to store and exchange data elements as discrete, cohesive units, OPACs are not compelled to display them as such. Coyle indicates, "Using the appropriate data structures, programs can derive a variety of displays and discovery elements from a single [MARC 21] field." ${ }^{\$ 3}$ Data storage and data display are two separate and distinct issues easily confused. For example, Attig has indicated that instead of confronting the critical problem of how to display multiple versions within automated catalogs, the Multiple Versions Forum participants presented a resolution for encoding and storing data about multiple versions. ${ }^{44}$ Confusing these two issues has represented a major stumbling block in developing pragmatic library database and display designs. Beacom states explicitly, "there are other ways to split and lump" the double-duty bibliographic records librarians need. ${ }^{45}$ $R D A$ could instruct catalogers to create manifestation level descriptions, but well-designed OPACs could then generate displays of all equivalent versions, as well as related works and expressions. Beacom believes the development of such capabilities within library OPACs is quite likely during 
the next ten years. Improving OPAC display capabilities holds the greater promise for helping librarians resolve the MulVer problem. Two specific initiatives, the FRBR conceptual model and the MARC 21 communications formats, may bring us even closer to this goal.

\section{The Potential of FRBR}

In 1998, the International Federation of Library Associations and Institutions' Section on Cataloging published the Functional Requirements for Bibliographic Records $(F R B R) .^{46}$ This document notes, "The study has two primary objectives. The first is to provide a clearly defined, structured framework for relating the data that are recorded in bibliographic records to the needs of users of those records. The second objective is to recommend a basic level of functionality for records created by national bibliographic agencies." ${ }^{\prime 7}$

$F R B R$ is not a draft standard, nor is it intended to replace AACR2 or any other cataloging code. FRBR is a systematic, international examination of automated catalogs and the records that comprise them. The study takes the form of a conceptual model and focuses upon three areas:

1. Bibliographic entities and the attributes necessary to describe and access them as well as to distinguish them unambiguously;

2. Relationships between and among bibliographic entities and the relationships bibliographic descriptions share with other external entities such as people, corporate bodies, and subjects; and

3. How users navigate among bibliographic records to find, identify, select, and obtain bibliographic resources within a national bibliography or a library catalog.

The first two focal points allow the model to establish recommendations for "a basic level of functionality for records created by national bibliographic agencies."48

To date, the bulk of intellectual effort on the part of library constituencies worldwide has been upon the first FRBR area, bibliographic entities and their attributes. Of these, the Group 1 entities (work, expression, manifestation, and item) have received by far the most attention. Despite this disproportionate interest in the FRBR lexicon and specifically the Group 1 entities, the FRBR model holds promise in two additional areas. First, FRBR is a conceptual model intended to help librarians consider the catalog more broadly, i.e., how individual records and the relationships among them contribute to the utility of the overall catalog. ${ }^{49}$ In essence, the FRBR model encourages librarians to think about catalogs rather than individual records. The second area of promise within FRBR now being more widely recognized is a renewed emphasis upon users and their needs.
Tillett and Smiraglia's work on bibliographic relationships will play a vital role in database design as libraries and ILMS systems implement FRBR-aware catalogs. ${ }^{50}$ Most librarians envision FRBR-aware catalogs based on these underlying relationship structures to be far easier and more intuitive for users to navigate and interpret.

\section{FRBR and $A A C R 2$}

Serials catalogers have been slow to familiarize themselves with FRBR and with how the model may benefit OPAC displays for serials and continuing resources. Antelman has illustrated many of the complexities associated with defining serial works and with developing serial identifiers adequate to address the needs of the library community, publishers, and abstracting and indexing services. ${ }^{51}$ FRBR's conceptual model is not a perfect match for current AACR2/CONSER serials cataloging, and further studies are needed to clarify some remaining uncertainties. How to define a serial work remains chief among the FRBR decisions needed from the AACR community. The decision is complicated by the fact that our library catalogs commonly contain serial bibliographic records described using several distinct cataloging conventions.

As we consider how the FRBR model may assist librarians and catalog designers improve OPAC displays for serial resources, another important consideration is how each of the FRBR Group 1 entities applies to serials. For many serial works, there is only one work, one expression, and one manifestation, but the potential for many, many items. For these serials, a FRBR-aware OPAC display does not differ significantly from a traditional OPAC display, and the MulVer problem is negligible. Other serials offer multiple manifestations in a range of language and regional editions. For serial works, each of these separate language and regional editions represents a separate expression, but the FRBR edition attribute is troublesome. For monographs and most other library resources, edition statements represent FRBR manifestation-level attributes. In the case of serials, the edition statement is sometimes an expression attribute, sometimes a manifestation attribute. Many serial expressions use what appear to be edition statements to represent numbering attributes (e.g., 2003 ed., and so on). Serial edition statements in this form represent manifestation attributes. Yet when a serial edition statement targets a specific audience (e.g., teacher's edition), a geographic region (e.g., Northeastern edition), or a language edition, the edition statement represents an expression-level attribute. These serial titles, available in multiple FRBR expressions and multiple physical formats, will benefit most from FRBR and MulVer-aware OPAC displays.

Within a FRBR-aware catalog, work and expression entities will exist only in what are today considered authority files. Exactly what form these serial work and expression 
identifiers will take remains an issue very much in debate. Antelman believes that "the [serial] work identifier should be a dumb number, unrelated to existing identifiers associated with the bibliographic entities that it describes, such as titles, [uniform titles], or ISSNs. ${ }^{.52}$ In contrast, many, including the JSC's FVWG, believe identifiers should be eye-readable uniform titles. One concern about our ability to uniformly assign serial work and expression identifiers is that currently many parallel pre-AACR2 and Successive Entry serial descriptions populate the CONSER database and local library catalogs. The choice of primary access point (i.e., citation) as well as the valid title variants upon serial records entered according to these two cataloging guidelines are different. ${ }^{53}$ Consequently, catalogers describing a new serial manifestation within an AACR2 environment for which there is an existing pre-AACR2 record for an equivalent manifestation are confronted with two unpleasant choices: either redescribe a functional pre-AACR2 record as Successive Entry to synchronize the two descriptions, or face the probability that the two records for these equivalent versions will have different primary access points and, therefore, different citations. From a FRBR perspective, two different primary access points represent two different works. The prospect of adopting a cataloging code requiring serial work and expression identifiers understandably gives serialists pause. Serials catalogers wonder if they will be required to create and accept multiple parallel serial work and expression identifiers if libraries continue to allow both pre-AACR2 and Successive Entry serial cataloging descriptions as valid components of library catalogs and bibliographic utilities. That is, for those serial expressions for which pre-AACR2 descriptions exist for one or more manifestations and Successive Entry descriptions exist for other manifestations, will serials catalogers be expected to create parallel work and expression identifiers for both primary access points when they differ?

What to do with these pre-AACR2 records is a complex problem because, like the MulVer problem, it crosses the boundary between AACR and MARC, and also extends from the bibliographic utilities into our local ILMS systems. The issue is further complicated by the fact that from a pragmatic point of view, these pre-AACR2 records remain functional. Because of significant differences between preAACR2 and Successive Entry rules for determining choice of entry, it may be advisable for the AACR/CONSER serials community to stop recognizing the validity of coexisting pre-AACR2 and Successive Entry serial descriptions. One prominent example of how pre-AACR2 and Successive Entry serial records differ is that most pre-AACR2 records do not contain uniform titles. Successive Entry serial records commonly contain a uniform title. As uniform titles affect how serial manifestations are cited and the form of their primary access points, parallel pre-AACR2 and
Successive Entry descriptions often result in catalog records for equivalent serial versions with different primary access points. Redescribing or recataloging these pre-AACR2 records as Successive Entry would allow serialists to synchronize the primary access points for all equivalent serial manifestations, thereby collocating each version of a serial work or expression. A policy change of this magnitude would be difficult. Arguing for redescribing serial records that function quite well at present is counterintuitive. That said, there is a strong impetus within the current $R D A$ enterprise recommending that an authority records exist for each serial work and expression. Momentum for this directive was furthered by the distribution draft for worldwide comment of the Functional Requirements for Authority Records (FRAR) conceptual model. ${ }^{54}$ With this in mind, one reasonable incentive for redescribing (i.e., recataloging) functional preAACR2 records may be that following revision, these presently functional records will operate even more efficiently far into the future. A CONSER Task Group on Non-AACR2 Records has been assembled to consider this and other concerns related to pre-AACR2 serial descriptions. ${ }^{55}$

Also, with the upcoming publication of $R D A$ scheduled for 2009 , some catalogers may fear that shortly after redescribing all pre-AACR2 serial descriptions as Successive Entry, they will face a similar maintenance initiative when $R D A$ is published. Though understandable, this argument against more consistent serial descriptions in our catalogs and utilities is flawed. During the serial rule revision process from 1998 through 2002, which followed the 1997 International Conference on the Principles and Future Development of AACR (commonly known as the Toronto Conference), several serial entry guidelines, including a return to Latest Entry cataloging, were considered, and Successive Entry serials cataloging was retained. ${ }^{56}$ It therefore appears unlikely that the cataloging rules for serials entry will change markedly (if at all) between the AACR2 2002 revision and the initial iteration of $R D A$. Nonetheless, guidelines for establishing FRBR and FRAR work and expression identifiers for serial resources, with specific regard to the pre-AACR2 and Successive Entry cataloging guidelines, merits further study.

\section{$F R B R$ and Serials}

Within the FRBR model, work and expression records contain only such universal attributes as a title or uniform title identifier, subject tracings, and other access points applicable to all manifestations. As FRBR-aware catalogs develop, the manifestation records linked to serial work and expression records will contain more specific descriptive information than the holdings records in today's catalogs. These records may include descriptive information and such identifier elements as ISSN and ISBN. ILMS systems 
will need to develop algorithms capable of searching across multiple levels of work/expression and manifestation entities as demonstrated by Mimno's hierarchical catalog project. ${ }^{57}$ That is, FRBR-aware catalogs must index and retrieve elements or attributes present in both the authority file (i.e., works and expressions) and in the bibliographic/holdings file where manifestation and item data resides. The final report of a recent CC:DA Task Force for the Review of IFLA's "Guidelines for OPAC Displays" recommends that ILMS systems generate result displays drawn from data within both the bibliographic and authority files. ${ }^{58}$ These result screens would aid user navigation while the dynamic linking capabilities of today's Web-based OPACs would reduce the number of redundant searches currently required of library catalog users.

ILMS systems also must be able to limit or refine search results based on data elements or attributes at each of these levels. As Yee says in compiling her 2004 MARC 21 shopping list, "put coded information currently in [the leader], 006, 007 and 008 fields in MARC 21 bibliographic and holdings records in the best possible place to allow ready access to both librarians and the public for direct searching of all kinds of categories for dates, language, country of origin, and physical format ... ${ }^{.59}$ This capability will empower those users who want to see only the online or print resources a library has available.

Much of the data necessary to generate FRBR-aware displays is encoded in MARC 21 catalog records. Bowen, chair of the FVWG, has stated that unique work and expression headings may not be constructed for every resource. ${ }^{60}$ Therefore, catalogers need to consider and suggest additional ILMS systems techniques of collocating and distinguishing works and expressions based on bibliographic and authority data in current library records. Unfortunately, the data within bibliographic records is not always as pristine or rich as librarians might wish. Bowen continues, "Another important lesson learned [by the FVWG] is that the success of projects to FRBRize existing MARC records depends upon the quality of the data [in those records]. ${ }^{361}$ One area that will have a direct impact on creating FRBR and MulVer displays is uniform title assignment. In exploring expression-level collocation, the JSC's FVWG demonstrated that uniform titles have tremendous potential as descriptive cataloging tags able to both collocate and distinguish related groups of works and expressions. Uniform titles for serials, though, are an AACR2 innovation. Most pre-AACR2 serial descriptions do not contain uniform titles and even within AACR2, assigning uniform titles remains optional for libraries. For those resource descriptions containing uniform titles, there are errant headings and incorrectly assigned headings. Such errors, requiring human review, will be costly to correct. (For example, see the discussion later in this paper concerning figures 2 and 3.)
Librarians need to help ILMS systems developers understand that in asking for FRBR-aware displays and MulVer-aware displays, we are asking for two distinct development lines. Creating a FRBR-aware OPAC display will not resolve the MulVer problem. As Jones has noted, FRBRaware OPACs will cluster related works, expressions, and manifestations more clearly, but will not free users of the need to consult multiple records for equivalent versions. ${ }^{62}$ FRBR-aware serial displays may display serial works available in multiple expressions and manifestations as a single entry within a headings list (see table 1). Users interested in selecting from among the available expressions of the New York Times or related works within a catalog could select an entry to expand this tree structure (see tables 1 and 2). They may then identify one of the available manifestations by expanding the tree structure yet again (see table 3). The resulting manifestation-level headings in turn may be expandable in cases where the microform manifestation may be available in microfiche and microfilm, and the electronic manifestation may be available as a CD-ROM, diskette, and online. For most works in library catalogs, FRBR-aware search results will be far less voluminous than this particular example. As of December 2001, an analysis of the OCLC WorldCat database projected that almost 80 percent of the approximately 32 million works available were represented by a single manifestation, and would therefore require no further FRBR-aware display modifications. ${ }^{63}$

An additional element ILMS software designers must bear in mind in order to limit redundant displays is the concept of attribute inheritance detailed in the FRBR model and further described by Coyle and Mimno. ${ }^{64}$ Coyle rightly insists that FRBR-based "identifiers allow the creation of functional records at any [entity] level as long as the rules of inheritance are obeyed, such that any lower level [entity] always inherits data elements from the level above it within its functional group." ${ }^{.65}$ FRBR-aware ILMS systems cognizant of the model's rules of inheritance will allow multi-tier records to generate clear, non-repetitive OPAC displays. This will contribute significantly toward creating OPACs that users are able to navigate and understand easily. Meanwhile MulVer-aware OPAC displays will require a different development effort as described following.

\section{FRBR and Multiple Versions}

Upon publication, FRBR generated considerable excitement within the library community. Many believed this fresh model would lead to a satisfactory resolution of the MulVer problem. After all, FRBR focuses largely upon relationships within catalogs and, as defined within Tillett's taxonomy, what closer relationship could two distinct bibliographic resources share than being equivalent versions? $?^{66}$ 
In 1997, when the FRBR document was still in draft form, Jones wrote an important paper reconsidering the MulVer problem in light of the FRBR model. ${ }^{67}$ Jones describes the MulVer problem for serials and concludes with the belief that the AACR community is moving with due deliberation toward the eventual goal of work level cataloging. In 2003, Coyle assessed the impact of FRBR on current development directions within the cataloging and library systems landscape as moving us toward work-level descriptions, or what she termed the "multi-level, multi-functional library systems record." ${ }^{.68}$

Numerous paths could lead to a work-level approach in cataloging. The cataloging community could revise AACR to advocate work-level descriptions, but as demonstrated above such a change would likely come at the expense of both critical current administrative functionality and the legacy manifestation-level data making up today's catalogs. A somewhat less radical approach might take advantage of the technological capabilities of a well-programmed ILMS able to process existing manifestation records in response to a user's query and generate both a FRBR and MulVeraware OPAC display.

In working with ILMS systems developers to create MulVer-aware OPACs, librarians must remind them of the distinct issues of data storage and data display. Libraries have compelling reasons to continue creating and storing bibliographic descriptions at the manifestation level, but these storage packets have nothing to do with how OPACs then display these data packets. For serial resources, a valuable display sequence would allow users to expand work tree structures to the expression level as described above. Upon selecting a particular serial expression, instead of retrieving multiple manifestation entries as in table 3, a MulVer-aware OPAC would assemble each of the manifestation attributes embodying a specific expression (e.g., the daily edition of the New York Times) and display them to the user as a single manifestation-neutral bibliographic description.
Table 2. FRBR-aware OPAC display for expressions of the New York Times work entity

\begin{tabular}{lll}
$\mathbf{w}_{1} \quad \begin{array}{l}\text { New } \text { York times } \\
\mathrm{e}_{1}\end{array}$ & Audio expression(s) & + \\
$\mathrm{e}_{2}$ & Daily expression(s) & + \\
$\mathrm{e}_{3}$ & Large-print expression(s) & + \\
$\mathrm{e}_{4}$ & Weekly expression(s) & + \\
\hline
\end{tabular}

Note: The + sign indicates that a particular entry may be expanded.

Table 3. FRBR-aware OPAC display for multiple manifestations (i.e., versions) of one expression of the New York Times work entity

\section{$w_{1} \quad$ New York times}

$\mathrm{e}_{1} \quad$ Daily expression(s)
$\mathrm{m}_{1} \quad$ Electronic manifestation(s)
$\mathrm{m}_{2} \quad$ Microform manifestation(s)
$\mathrm{m}_{3} \quad$ Print manifestation(s)

Note: The + sign indicates that a particular entry may be expanded. 
This expandable tree-structure entry for serial works within FRBR-aware and MulVer-aware OPAC displays would represent a significant improvement over the multiple hits serial searches often retrieve in today's OPACs. This tree-like display for works with multiple expressions or manifestations represents one of the most intriguing potential features of the FRBR model for library OPACs. With time and development, ILMS systems should soon be able to offer pre- or post-search features allowing users to identify and select the specific resource of interest. Yee has implemented a catalog of moving image materials similar to the one envisioned previously. According to an e-mail message announcing the availability of the UCLA Film and Television Archive catalog, Yee and her staff have cataloged moving image materials at the expression level and then attached multiple MARC 21 holdings records representing physical format variations as well as other slight manifestation-level differences. ${ }^{69}$ The Film and Television Archive at UCLA captures manifestation-level title variations by building work-level authority records with extensive crossreferences.

To further illustrate the feasibility for such innovative OPAC display technology, consider the results of a cooperative project between the California Digital Library (CDL), the State University of New York (SUNY) system, and Ex Libris. $^{70}$ Individual libraries within these two consortia retain manifestation-level records for titles within their local OPACs. For users of the MELVYL (CDL) and SunCat (SUNY) union catalogs, separate manifestation-level records are consolidated through Ex Libris to display a single work or expression-level record detailing the holding institutions and the separate manifestations each holds.

With OCLC's FictionFinder and Curioser projects, librarians are seeing the first commercial and research applications of the FRBR model to catalogs of existing records ${ }^{71}$ At least one major ILMS vendor currently offers a FRBR OPAC. VTLS's Virtua offers libraries the option of implementing the expandable/collapsible FRBR displays discussed in this paper. Other ILMS vendors have FRBR applications in development. Unfortunately, FRBR implementations thus far include only relatively small subsets of the available bibliographic universe of records, and none of the production versions of these products contain any serial works or expressions. ${ }^{72}$

\section{The Promise of MARC 21}

FRBR is not the only option for libraries intent on improving today's OPAC displays in response to user needs. For all of its potential, any significant and widespread implementation of FRBR precepts into cataloging codes and integrated library systems remains years away. Meanwhile, other ways of adopting work and expression-level displays in library OPACs offer potential improvements. The MARC 21 authority, bibliographic, and holdings formats provide one alternative. The MARC 21 authority format represents one possible medium for communicating and exchanging work and expression identifiers. Work and expression identifiers are critical for colocating manifestation-level descriptions, descriptions that multiply to create the MulVer problem. The current Library of Congress Action Plan contains the following near-term goal as one of the recommendations suggested at the November 2000 Bicentennial Conference on Bibliographic Control in the New Millennium: "Develop [the] functional requirements to enable the interchange of manifestation records that support internal [i.e., ILMS OPAC] configurations for FRBR (IFLA Functional Requirements for Bibliographic Records) displays for multiple versions; determine supportive cataloging practices; determine any needed MARC 21 enhancements; communicate these to the vendor community." ${ }^{\text {"73 }}$ Yee's article addressing FRBR-aware displays offers specific guidance to ILMS software designers for assembling work and expression identifiers from existing MARC 21 data elements in the bibliographic and authority records in today's library catalogs. ${ }^{74}$ Yee's proposed OPAC displays for these identifiers bear little resemblance to how these MARC 21 fields and subfields are stored and exchanged, providing further evidence of the important distinction between data storage and data display.

Some complexities are inherent to developing serial identifiers, and varying interpretations remain regarding how these identifiers should be formulated. For the purposes of this paper, presume that the FVWG uniform title approach is selected. Frequent overlap among serial bibliographic and authority records describing the same work or expression occurs, notably with regard to monographic series, which are by definition also serials. Many of these titles have a serial record in the bibliographic file and a corresponding series authority record (SAR) in the Library of Congress, Name Authority File (LC/NAF). In theory, the citation/primary access point on these two records should match, but for reasons previously cited and having to do mostly with the current acceptance of several contradictory serial entry guidelines, this is not always the case. For example, see figures 2 and 3 , representing an LC/NAF series authority record (figure 2) and a CONSER bibliographic record for the same work (figure 3). The qualifiers in the uniform title headings do not match. In FRBR terms then, these two headings intended to cite a single work represent two separate works. Such inconsistencies in work and expression headings foster confusion for both internal and external library users. ${ }^{75}$ While this poor heading construction is not a direct result of the MulVer problem, it certainly represents one indirect consequence. Within 
enormous bibliographic utilities and catalogs where uniform title entries are required to collocate and distinguish numerous serial works and expressions, the potential for inconsistent heading assignment and construction increases. Inconsistent uniform titles then fail to fully collocate the multiple serial expressions within our intricately constructed catalogs. The resulting failure of library OPACs to clearly fulfill both the collocating and distinguishing roles required of uniform title work and expression identifiers leads to user confusion. As libraries move toward work and expression-level OPAC displays, these inconsistent work and expression headings must be corrected. As with the uniform titles previously discussed, many of these inconsistencies between bibliographic uniform titles and series authority records may require human review. Looking ahead, the IFLA Functional Requirements for Authority Records (FRAR) document currently being drafted must emphasize the importance of keeping such headings in accord. ${ }^{76}$

If libraries choose to resolve the MulVer problem by pursuing a multi-tier approach, creating work and expression-level OPAC displays with manifestation-specific details appended within holdings records, each of the MARC 21 formats will require further development. As Eversberg has indicated in response to the FRBR model, "If it comes to a work-oriented approach, the whole dichotomy of bibliographic vs. authority records [must] be re-evaluated." 77 Referring to the potential of her proposed multifunctional record, Coyle says, "It is reasonable to assume that a future cataloging structure will embody some degree of hierarchy, especially in the need to express the relationships between multiple versions of the same work." ${ }^{.78}$ Two serial-specific issues currently under consideration will be critical if libraries pursue this path toward resolving the MulVer problem: the existence of multiple serial entry guidelines and

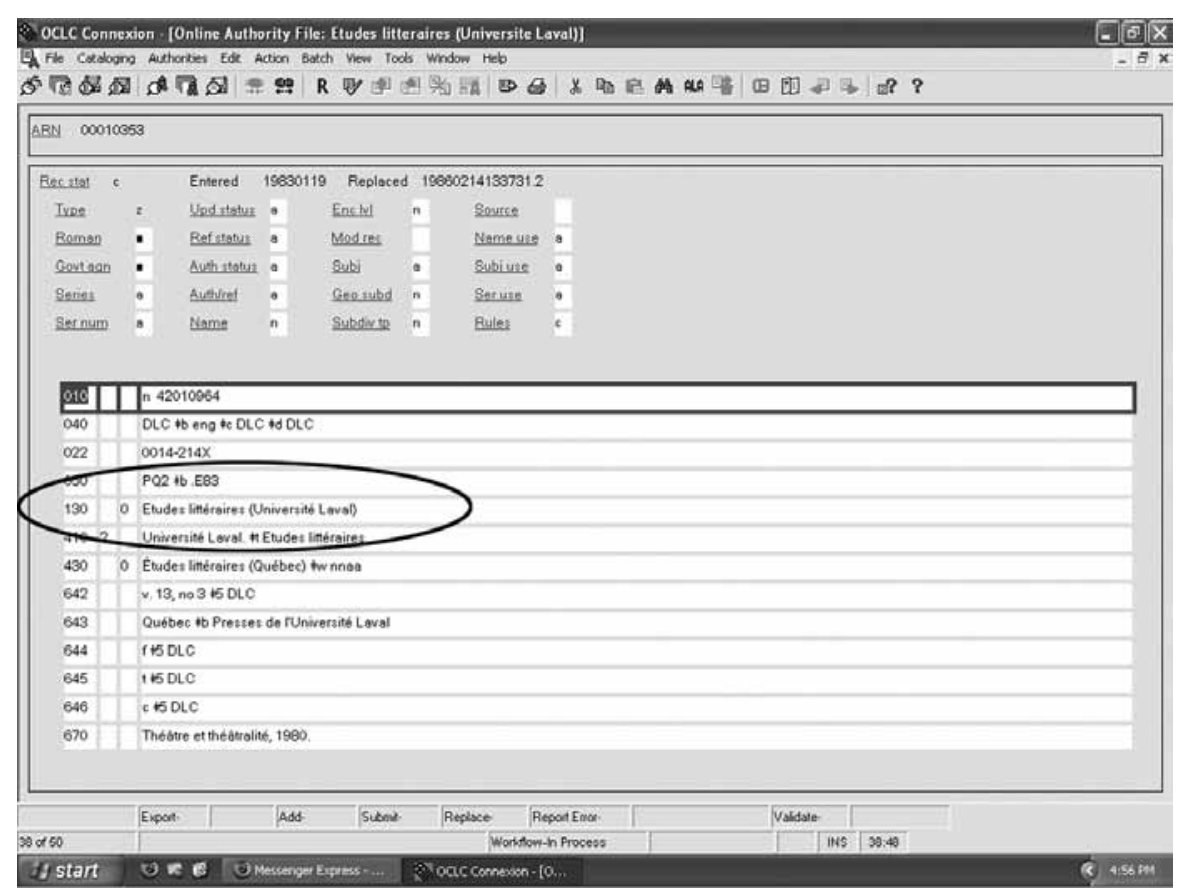

Figure 2. Example of an LC/NAF series authority record out of sync with a corresponding CONSER bibliographic record (shown in figure 3)

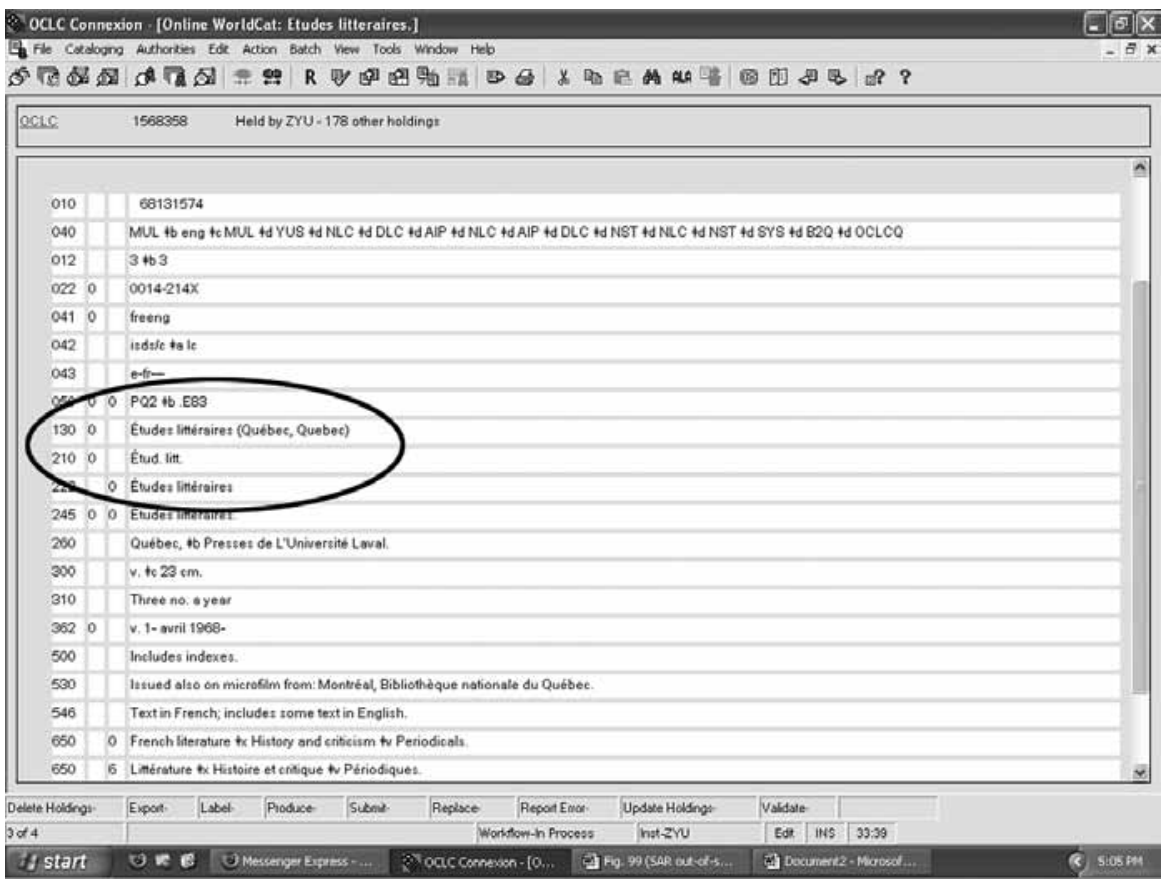

Figure 3. Example of a CONSER serial record that is out of sync with the corresponding LC/NAF series authority record (SAR) (Some fields have been removed from this record display for formatting purposes.) 
proposals to approve multiple 1XX fields within authority records.

Though most libraries have followed Successive Entry cataloging since 1981, Latest Entry and pre-AACR2 serial records continue to reside with Successive Entry records in library catalogs and bibliographic utilities. Pre-AACR2 serial records and their effects upon creating serial work and expression identifiers were discussed previously. In Latest Entry cataloging, the latest known title is entered in the 245 field (Title statement). Previous titles are in 247 fields (Former title). One could reasonably argue that even though these title entries exist at the bibliographic as opposed to the authority level, Latest Entry records currently serve as serial work identifiers in documenting and indexing each known title change for entire serial runs. Whether a user searches the current title or a former title within a catalog containing Latest Entry records, a properly indexed ILMS will retrieve the requested record. As such, the AACR community could make the policy decision that these Latest Entry records will remain intact, and that catalogers will not create authority work or expression identifiers for the titles they represent. A cataloging community policy decision of this sort would have little or no impact on MARC 21 format development.

A second important serial-related issue regards the ramifications of authenticating multiple 1XX fields within series authority records. When trying to reconceptualize library catalogs as user-friendly interfaces, one of the fundamental flaws with Successive Entry serials cataloging is the ability to link and display only to the immediately preceding and succeeding titles. The resulting displays make it difficult for library users to navigate among the manifestation records representing a serial run. Yee characterizes this limitation as a series of precarious stepping stones-if any of the titles, or stones, is missing within the catalog being searched, the serial run cannot be assembled. ${ }^{79}$

This practice is paralleled within name authority records (including series headings). The records contain one 1XX field and, potentially, one preceding 5XX entry and one succeeding $5 \mathrm{XX}$ entry. If the MARBI Committee were to approve series authority records containing multiple $1 \mathrm{XX}$ fields, catalogers could represent entire serial runs upon a single work/expression record. This redefinition of the series authority record would eliminate the need to delineate earlier and later titles through the 5XX stepping-stone mechanism, and would simultaneously decrease the number of authority records required to represent serial title runs. By linking the appropriate authorized 1XX field to each bibliographic manifestation of a serial work or expression, all would be clustered and displayed for selection by the user. OPAC users searching the serial title from article citations would retrieve a single work/expression entry displaying all linked manifestations available within the catalog, greatly facilitating navigation through complex serial displays.
Whether these serial manifestations are described in MARC 21 bibliographic or holdings records is another area requiring further study. The format could develop to support either, but one scenario, presented by Tillett at a 2005 IFLA FRBR Review Group Workshop, completely removes the bibliographic entity from the catalog. ${ }^{80}$ Works and expressions are formulated through MARC 21 authority records. Manifestation and item information is represented through the MARC 21 holdings format, and these holdings records are then attached directly to authority records. ${ }^{81}$

This scenario has generated interest because it would provide a more clearly defined communications standard for the attributes common to serials. Serial bibliographic records in today's OPACs contain an array of data elements representing FRBR work, expression, and manifestation attributes. Describing serial work and expression attributes in authority records in a central, shared catalog such as LC/ NAF would allow individual libraries to attach their specific manifestation and item information in locally maintained but universally-accessible (i.e., viewable) holdings records. As Tillett says:

If we had a clear way of identifying the attributes for a particular work/expression/manifestation/item combination, we could theoretically [present] all such combinations for the same work in a single record, and display [only] the needed elements as the application or user specified. There are many ways this could work. ${ }^{82}$

The MulVer problem could be resolved with the MARC 21 authority, bibliographic, and holdings formats. By authenticating multiple 1XX fields in series authority records, the format also could help resolve the cumbersome display and navigational shortcomings of today's AACR2 Successive Entry serials record displays. In order to optimize such a proposal, further development would be required in at least three areas:

1. MARC 21 format development to provide greater flexibility in how libraries distribute bibliographic attributes among authority, bibliographic, and holdings record structures;

2. ILMS and systems development to facilitate the indexing and display of data elements across MARC 21 structures; and

3. Utility (i.e., OCLC) and ILMS development to allow libraries to exchange complex, multi-tier records.

Frustrated with the lack of concerted development initiatives on the part of both the library community and ILMS vendors, some libraries have adopted practices and policies enhancing OPAC displays and addressing user needs within 
their local catalogs. For instance, the UCLA Film and Television Archives creates expression-level records for moving image materials and attaches holdings records to represent separate manifestations. In response to strong user and subject bibliographer preferences, New York University (NYU), routinely attaches all serial manifestations held by or accessible through the library to a single serial work or expression description. Each equivalent manifestation is then recorded and displayed through a separate MARC 21 holdings record. Every serial holdings record in NYU's catalog contains at least the first two bytes of a 007 tag so the specific material designation (SMD) or carrier information of each is clearly displayed for users (e.g., text, online, CD-ROM, microfiche, and so on). Figure 4 represents an example serial record from NYU's OPAC. Note the use of multiple "Library has" statements detailing numerous holding locations and formats directly on the print bibliographic description. In the MARC record, these "Library has" statements are generated through multiple 866 fields (Summary Holdings Statement). NYU's ability to pursue this aggressive single-record technique for serial resources is facilitated by the Geac ADVANCE ILMS's capability of attaching multiple serial receiving records to separate holdings records upon a single serial bibliographic description. In other words, for a serial title that NYU holds current subscriptions for print, online, and microfiche manifestations, ADVANCE enables our Serials Receiving Unit to order, receive, and check in the individual manifestation issues upon separate holdings records attached to a single bibliographic description. This receipt history is displayed in detail for OPAC users through the separate MARC 21 Holdings records attached to the single bibliographic description.

If librarians are prepared to reconsider the AACR community's approach to cataloging manifestations and simultaneously demand revolutionary OPAC displays from ILMS vendors, it may be possible to avoid the requirement of exchanging complex, multi-tier records. When Attig and Yee independently proposed this idea several years ago, its realization seemed decades away. ${ }^{83}$ Yet computing has rapidly become so powerful, so ubiquitous, and so much less expensive that implementing such a system may be closer than we think. In his paper for Svenonius's Conceptual Foundations of Descriptive Cataloging, Attig implicitly referred to the idea of a single, centralized catalog, envisioning an Elysian future wherein all catalogers would contribute to the same authority files and a single bibliographic catalog. ${ }^{84}$

While most AACR2 libraries today take advantage of the centralized authority database represented by the LC/

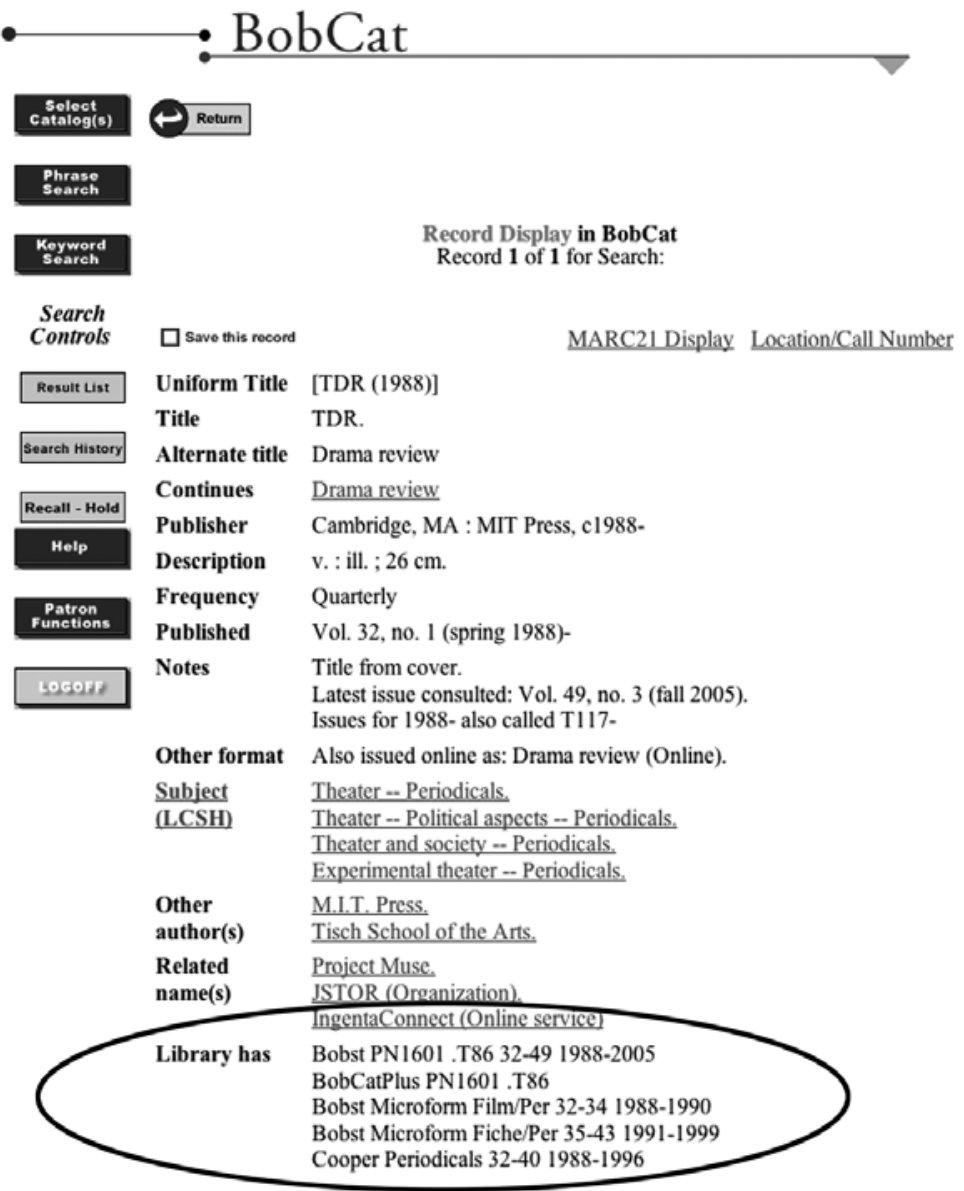

Figure 4. Sample single-record serial display within NYU's BobCat OPAC (The record display has been modified in order to compress elements of interest on a single screen.)

NAF, each library's individual catalog, made up of contextually specific authority, bibliographic, and holdings records, remains completely disparate, and therefore isolated - connected and networked, but alone. As the AACR community moves toward implementing a cataloging code based largely upon the FRBR conceptual model and mindful of displaying the relationships among records and entities, this tension, as Attig calls it, between work input cooperatively and shared at the national or international level, and work that must then be replicated locally, will become increasingly redundant and frustrating. ${ }^{85}$

In her contribution to the 1995 ALCTS preconference, "The Future of the Descriptive Cataloging Rules," and again in her paper for the 1997 Toronto Conference, Yee sounds a more explicit call for a single shared catalog. ${ }^{86}$

The real problem with all linking devices in a shared cataloging environment, however, lies with the shared cataloging environment itself . . . The 
real solution . . . is that instead of sharing cataloging records, we need to reexamine the possibility of sharing a catalog! . . If the development of the information superhighway eventually means cheap and ubiquitous telecommunication, could we not begin to envision a single catalog, accessible to all users, and updatable by all catalogers? ${ }^{87}$

The practical appeal and cost-effectiveness of a centralized, shared interface are difficult to ignore. During the serial rule revisions that followed the 1997 Toronto Conference and culminated with the revision of AACR2 Chapter 12 for Continuing Resources in 2002, the goal of just such a catalog was raised several times. Cooperative cataloging pushed to individual holding libraries is especially attractive for serials catalogers because of the ongoing bibliographic and holdings maintenance required by title changes and the issuance of serial resources over time. The centralized, distributed catalog envisioned by Attig and Yee would make such updating automatic. Each time users retrieved a serial title within this shared, centralized catalog, they would receive the most current bibliographic and holdings data available regardless of whether the latest updates were input locally or by another cataloger across the country or globe.

Further demonstrating how change remains the only true constant and just how quickly change occurs, recent merger announcements between OCLC and RLG and the subsequent consolidation of the Endeavor and Ex Libris ILMS systems will certainly have far-reaching implications for library workflows and processing. ${ }^{87}$ Exactly what these combined interfaces may offer future librarians will take months or even years to determine. With a single, shared bibliographic utility in place though, the feasibility of this centralized, shared catalog interface remains one possibility.

Incorporating one of the MulVer solutions presented in this paper within this centralized catalog would produce an interface offering a win-win situation for all library players. Library administrators would like the lower cost structure, catalog librarians would feel empowered by entering realtime contributions in a single, shared catalog, and reference librarians and users would enjoy access to all available cataloged resources. Probably the only current players likely to be displeased with this new central catalog would be the ILMS vendors. Had ILMS vendors shown the initiative necessary to provide libraries with technologically enhanced ILMS systems and OPAC displays during the last fifteen years, libraries would not still be seeking solutions to display problems endemic to the automated catalog environment.

If many of these recommendations and proposals seem familiar, they should. In his 1989 paper titled, "Descriptive Cataloging Rules and Machine-Readable Record Structures: Some Directions for Parallel Development," Attig called upon the AACR and MARC communities to codify the nec- essary principles and to explore the systems design required to enable the cataloging code and the then newly developed USMARC Holdings format to resolve the MulVer problem. ${ }^{89}$

\section{Conclusion}

Schottlaender has discussed calls for Rule 0.24 reform on behalf of the AACR2 community dating back to the earliest multiple versions discussions. ${ }^{90}$ This reform movement reached a new high at the 1997 Toronto Conference wherein "it was clear that 'The Cardinal Principle' was a basic and pressing problem." ${ }^{.91}$ As this paper illustrates, the JSC has now received similar messages from several user communities regarding this pressing problem for several years. The 1989 Multiple Versions Forum was a faint rumble. At the 1997 Toronto Conference, several papers and many presenters expressed continuing and mounting displeasure with AACR2's cardinal principle. Then, within fairly rapid order, two additional publications expressed dissent within the cataloging community: ISBD (ER) sanctioned multiple manifestations on single bibliographic descriptions in 1997, and the FRBR model in 1998 demonstrated an eagerness to consider overall catalogs in new ways with specific emphasis upon the needs of users. ${ }^{92}$ In 2003, the IFLA Cataloguing Section responded with a series of referenda in the form of International Meetings of Experts designed to solicit input and feedback on the feasibility of an internationally coordinated cataloging code. ${ }^{93}$ In something of a disappointment to librarians advocating the potential of FRBR and a more radical dismantling of the AACR2 Rule 0.24, the first International Meeting of Experts for an International Cataloguing Code (IME-ICC) held in Frankfurt among the European and American cataloging experts reaffirmed an insistent adherence to manifestation-level cataloging. ${ }^{94}$

As for the MulVer issue within the AACR community that today's primitive, manifestation-level OPAC displays perpetuate, this paper has explored three approaches to the problem, two long-term and another that could be explored and perhaps implemented more quickly. First, the revision of AACR and the eventual role Rule 0.24 may play within $R D A$ is a long-term solution, for the expected publication date of the new cataloging code is 2009. Second, FRBR and its eventual impact upon the cataloging code are linked with this 2009 AACR/RDA timeline. Nonetheless, FRBR is already exerting influence on user interfaces and the future development initiatives ILMS vendors are considering. It seems quite likely that while the new cataloging code in 2009 will continue to instruct catalogers to build manifestation-level bibliographic descriptions, FRBR's greater influence may be upon how ILMS system designers develop 
OPACs to cluster these manifestation-level descriptions into work and expression-level displays for users.

The third and more immediate resolution to the MulVer problem may reside with the MARC 21 communications formats. Libraries are constantly exploring this option within their local ILMS systems. Local resolutions to these ongoing problems are exemplified by initiatives at NYU and the UCLA Film and Television Archives. Within today's cooperative cataloging environment containing shared bibliographic utilities, centralized authority files and distributed, separate institutional catalogs however, these initiatives stand out and, in some ways, prove problematic. These solutions are not perfect, but the current obstacles to fine-tuning them result more from a lack of development by ILMS designers in their indexing and OPAC display capabilities than from significant conceptual problems with work or expression-level displays.

Ultimate resolution to the MulVer problem resides with ILMS OPAC displays. For a number of practical reasons described in this paper, not least of which is the need to preserve the link between the OPACs of tomorrow and the millions of manifestation-level bibliographic records populating catalogs today, manifestation-level descriptions will remain the data packets libraries use to store and exchange records. The necessity for libraries to store and exchange data as cohesive manifestation-level descriptions though in no way forces OPACs to display data in the same way. ILMS vendors do so because it is easy and because librarians have not uniformly insisted they do otherwise. Librarians must cease this passive acceptance of the inferior OPAC displays bundled with today's ILMS systems. Nonetheless, librarians must also bear partial responsibility for the failure of ILMS OPAC displays to develop further during the last twenty-five years. While it is easy to point the finger at library ILMS vendors, librarians have failed to present ILMS software designers with a cohesive vision of how OPAC displays should be improved. That time must end now. The pace of technological innovation across an array of professions and industries during the last fifteen years has been astounding. Libraries cannot afford to be left behind. Librarians must demand smarter displays from ILMS vendors, but they must be prepared to provide software designers with the direction necessary to develop such displays. Each of the millions of bibliographic and authority records in our catalogs represent rich data mines awaiting exploration and greater utilization. Yee's recent analysis using existing MARC 21 records to generate work and expression identifiers in order to clarify OPAC displays for users is exemplary and should be required reading for ILMS designers, librarians, and library school students. ${ }^{95}$

Are these issues complex? Of course they are, but complex issues should not require UCLA's Film and Television Archives to process moving image materials differently, or NYU to process serial resources differently than other library materials in order to fulfill their user's needs. Historically, cataloging solutions within local settings have driven national and international policies. For example, the CONSER single-record approach and the aggregator-neutral record grew out of individual libraries solving complex problems for users in practical ways through local OPAC displays. It is time for librarians to determine if solutions to issues like the MulVer problem are complex because they have to be, or complex because librarians perpetuate practices that make them complex. What users need is simple. They need consistent access to content. Within today's world of proliferating information carriers, providing consistent access to the content users seek is inherently complex, but to users it must appear simple. The job of today's librarians is to apply complex solutions to attain apparent simplicitycall it the Zen of librarianship. For librarians to require or expect users to continue to learn or assimilate anachronistic procedures based on antiquated practices is unrealistic and threatens to render library catalogs and collections irrelevant. In fact, such expectations violate the purposes of the catalog formulated by Cutter and furthered by Lubetzky. In considering simple, consistent OPAC displays for users of our increasingly complex bibliographic catalogs, librarians and catalog designers would do well to consider the words of Dempsey:

The benefits of a more consistent [OPAC display] are clear: [Librarian's] time and resources should be freed to think about collection and use of the collection, not consumed by the messy mechanics of acquisitions and processing; and the user experience should be shaped by learning and research needs not by the arbitrary constraints of interface and format. [Libraries] need to achieve the [economies] of consistent treatment as well as the benefits of consistent access. ${ }^{96}$

\section{References}

1. Anglo-American Cataloguing Rules, 2nd ed., 1998 rev. (Ottawa: Canadian Library Assn.; London: Library Assn. Publishing; Chicago: ALA, 1998).

2. IFLA Study Group on the Functional Requirements for Bibliographic Records, Functional Requirements for Bibliographic Records: Final Report, UBCIM Publications, New Series, vol. 19 (Munich: K. G. Saur, 1998). www.ifla .org/VII/s13/frbr/frbr.pdf (accessed July 28, 2006).

3. Seymour Lubetzky, Principles of Work Cataloging, Final Report, Phase I, Descriptive Cataloging (Los Angeles: UCLA, 1969).

4. Kristin Antelman, "Identifying the Serial Work as a Bibliographic Entity," Library Resources \& Technical Services 48, no. 4 (2004): 238-255. 
5. International Federation of Library Associations and Institutions, "Family of ISBDs (as of June 2004)," www.ifla. org/VI/3/nd1/isbdlist.htm (accessed Mar. 26, 2007); ISSN Manual: Cataloguing Part (2003). www.issn.org/files/active/0/ manual.pdf (accessed Mar. 26, 2007).

6. Anglo-American Cataloguing Rules, 2nd ed., 1998 rev., 8.

7. Crystal Graham, "Definition and Scope of Multiple Versions," Cataloging \& Classification Quarterly 11, no. 2 (1990): 5-32; Patrick Wilson, "The Second Objective," in The Conceptual Foundations of Descriptive Cataloging, ed. Elaine Svenonius, 5-16 (San Diego: Academic Press, 1989); Lynne C. Howarth, "Content versus Carrier," in The Principles and Future of AACR: Proceedings of the International Conference on the Principles and Future Development of AACR, Toronto, Ontario, Canada, October 23-25, 1997, ed. Jean Weihs, 148-156 (Chicago: ALA, 1998); Chris Oliver, "FRBR Is Everywhere, But What Happened to the Format Variation Issue? Content versus Carrier in FRBR," The Serials Librarian 45 , no. 4 (2004): 27-36.

8. Graham, "Definition and Scope of Multiple Versions," 9.

9. John C. Attig, e-mail message to the author, July 9, 2005.

10. Matthew Beacom, "Crossing the Digital Divide: AACR2 and Unaddressed Problems of Networked Resources," in Proceedings of the Bicentennial Conference on Bibliographic Control for the New Millennium, Washington, D.C., Nov. 1517, 2000, ed. Ann M. Sandberg-Fox, 135-154 (Washington, D.C.: Library of Congress, Cataloging Distribution Service, 2001): 140. www.loc.gov/catdir/bibcontrol/beacom.html (accessed Nov. 22, 2005).

11. Anglo-American Cataloguing Rules, 2nd ed., 2002 rev. (Ottawa: Canadian Library Assn.; London: Library Assn. Publishing; Chicago: ALA, 2003): I-2.

12. Howarth, "Content versus Carrier," 150.

13. Library of Congress, Cataloging Policy and Support Office, Cataloging Service Bulletin 81 (summer 1998): 20-21.

14. Cooperative Online Serials Program, CONSER Cataloging Manual, 2002 ed. Module 31. Online Serials (Washington, D.C.: Library of Congress, 2002): 14-15.

15. Cooperative Online Serials Program, CONSER Cataloging Manual, 2002 ed. Module 33. Newspapers (Washington, D.C.: Library of Congress, 2002): 56-57.

16. Cooperative Online Serials Program, CONSER Cataloging Manual, 2002 ed. Module 31. Online Serials (Washington, D.C.: Library of Congress, 2002): 15-19.

17. CONSER Operations Committee Meeting, May 5-6, 2005. Summary. www.loc.gov/acq/conser/conop2005.html\#13 (accessed July 23, 2005).

18. ALA Response to 5/JSC/AACR3/1(draft of Part 1 of AACR3), 132. (As of Nov. 19, 2005, access to this document remained restricted.)

19. Charles Ammi Cutter, Rules for a Printed Dictionary Catalog, U.S. Bureau of Education Special Report on Public Libraries, Part II. (Washington, D.C.: Government Printing Office, 1876).

20. Graham, "Definition and Scope of Multiple Versions," 5-32.

21. Carol Mandel, "Cataloging for Access," in Access Services: The Convergence of Reference and Technical Services, ed. Gillian M. McCombs, 61-68 (Binghamton, N.Y.: Haworth Press, 1991).
22. Amy K. Weiss, "Proliferating Guidelines: A History and Analysis of the Cataloging of Electronic Resources," Library Resources \& Technical Services 47, no. 4 (2003): 171.

23. Library of Congress, Network Development and MARC Standards Office, Multiple Versions Forum Report (Washington, D.C.: Library of Congress, 1990).

24. Ibid., 6 .

25. Michael Kaplan, "Serial Aggregations, Multiple Versions, and the Virtual Union Catalog: The California Digital Library Catalog, SUNY, and the Ex Libris Experiences," The Serials Librarian 46, no. 1/2 (2004): 69-82.

26. Howarth, "Content versus Carrier."

27. John C. Attig, "Multiple Versions Issues: A Blast from the Past," e-mail to the CC:DA Multiple Versions Task Force, 1993. www.libraries.psu.edu/tas/jca/ccda/tf-024c.html (accessed Nov. 21, 2005).

28. Ibid.

29. Association for Library Collections \& Technical Services, Cataloging \& Classification Section, Committee on Cataloging: Description \& Access Task Force on Rule 0.24, Overview and Recommendations Concerning Revision of Rule 0.24, Aug. 16, 1999. www.libraries.psu.edu/tas/jca/ccda/ docs/tf-024h.pdf (accessed Nov. 22, 2005).

30. International Federation of Library Associations and Institutions, $\operatorname{ISBD}($ ER): International Standard Bibliographic Description for Electronic Resources. Revised from the $\operatorname{ISBD}(\mathrm{CF})$ : International Standard Bibliographic Description for Computer Files. Recommended by the $\operatorname{ISBD}(\mathrm{CF})$ Review Group (Originally issued by K. G. Saur, Munich, 1997, as Vol. 17 in the UBCIM Publications, New Series). www.ifla .org/VII/s13/pubs/isbd.htm (accessed Mar. 26, 2007).

31. Weiss, "Proliferating Guidelines," 178.

32. Association for Library Collections \& Technical Services, Cataloging \& Classification Section, Committee on Cataloging: Description \& Access Task Force on Rule 0.24, Overview and Recommendations Concerning Revision of Rule 0.24, 6 .

33. Joint Steering Committee for Revision of Anglo-American Cataloguing Rules, "Current Activities." www.collectionscanada.ca/jsc/current.html (accessed July 25, 2005).

34. Oliver, "FRBR is Everywhere."

35. Library of Congress, Network Development and MARC Standards Office, MARC 21 Format for Holdings Data. 2005 Edition. (Washington, D.C.: Library of Congress, 2000). www.loc.gov/marc/holdings/echdhome.html (accessed Mar. 26, 2007).

36. Howarth, "Content versus Carrier."

37. Antelman, "Identifying the Serial Work," 251.

38. Deanna B. Marcum, "The Future of Cataloging," Library Resources \& Technical Services 50, no. 1 (2006): 8.

39. Howarth, "Content versus Carrier."

40. Martha M. Yee, "FRBRization: A method for Turning Online Public Finding Lists into Online Public Catalogs," Information Technology and Libraries 24, no. 3 (2005): 88.

41. Ibid.

42. Wilson, "The Second Objective."

43. Karen Coyle, "Future Considerations: the Functional Library Systems Record," Library Hi-Tech 22, no. 2 (2004): 170.

44. John C. Attig, e-mail message to the author, July 9, 2005.

45. Beacom, "Crossing the Digital Divide," 142. 
46. International Federation of Library Associations and Institutions Study Group on the Functional Requirements for Bibliographic Records, Functional Requirements for Bibliographic Records: Final Report, 7.

47. Ibid.

48. Ibid.

49. Patrick Le Boeuf, "FRBR and Further," Cataloging \& Classification Quarterly 32, no. 4 (2001): 15-52.

50. Barbara B. Tillett, "A Taxonomy of Bibliographic Relationships," Library Resources \& Technical Services 35, no. 2 (1991): 150-158; Richard P. Smiraglia, "Derivative Bibliographic Relationships: Linkages in the Bibliographic Universe," in Navigating the Networks: Proceedings of the ASIS Mid-Year Meeting, Portland, Oregon, May 21-25, 1994, ed. Deborah Lines Anderson, Thomas J. Galvin, and Mark D. Giguere, 167-183 (Medford, N.J.: ASIS, 1994).

51. Antelman, "Identifying the Serial Work."

52. Ibid., 249.

53. Cooperative Online Serials Program, CONSER Cataloging Manual, 2002 ed. Module 21. Modifying Records (Washington, D.C.: Library of Congress, 2002).

54. International Federation of Library Associations and Institutions UBCIM Working Group on Functional Requirements and Numbering of Authority Records (FRANAR), Functional Requirements for Authority Records [draft 2005/06/15]: A Conceptual Model. www.ifla.org/VII/d4/ wg-franar.htm (accessed Aug. 11, 2005).

55. Cooperative Online Serials Program, CONSER Task Group on Non-AACR2 Records. (rev. Aug. 2005). www.loc.gov/acq/ conser/charge-preA2.html (accessed Nov. 22, 2005).

56. International Conference on the Principles and Future of the Development of AACR (1997). www.collectionscanada.ca/jsc/ intlconf.html (accessed Mar. 26, 2007); The Principles and Future of AACR: Proceedings of the International Conference on the Principles and Future Development of AACR: Toronto, Ontario, Canada, October 23/25, 1997, ed. Jean Weihs. (Ottawa: Canadian Library Assn.; London: Library Assn. Publishing; Chicago: ALA, 1998).

57. David Mimno, Gregory Crane, and Alison Jones, "Hierarchical Catalog Records: Implementing a FRBR Catalog," DLib Magazine 11, no. 10 (Oct. 2005). www.dlib.org/dlib/ october05/crane/10crane.html (accessed Dec. 22, 2006).

58. Association for Library Collections \& Technical Services, Cataloging \& Classification Section, Committee on Cataloging: Description \& Access, Task Force for Review of “Guidelines for OPAC Displays," Report (Jan. 30, 2004). www.libraries.psu.edu/tas/jca/ccda/tf-opac04a.html (accessed July 27, 2005).

59. Martha M. Yee, "New Perspectives on the Shared Cataloging Environment and a MARC 21 Shopping List," Library Resources \& Technical Services 48, no. 3 (2004): 11-12.

60. Jennifer Bowen, "FRBR: Coming Soon to Your Library?" Library Resources \& Technical Services 49, no.3 (2005): 175-188.

61. Ibid., 183.

62. Edgar A. Jones, "Multiple Versions Revisited," Serials Librarian 32, no. 1/2 (1997): 177-198.

63. Rick Bennett, Brian F. Lavoie, and Edward T. O’Neill, “The
Concept of a Work in WorldCat: An Application of FRBR," Library Collections, Acquisitions \& Technical Services 27, no. 1 (2003): 45-59.

64. Coyle, "Future Considerations"; Mimno, Crane, and Jones, "Hierarchical Catalog Records."

65. Coyle, "Future Considerations," 172.

66. Tillett, "A Taxonomy of Bibliographic Relationships."

67. Jones, "Multiple Versions Revisited."

68. Coyle, "Future Considerations," 167.

69. Martha M. Yee, "UCLA Film and Television Archives on Voyager," e-mail to FRBR listserv, July 9, 2004. www.ifla .org/VII/s13/wgfrbr/archive/FRBR_Listserv_Archive.pdf (accessed Oct. 9, 2006).

70. Kaplan, "Serial Aggregations"; Michael Kaplan, "Exploring Partnerships: What Can Producers and Vendors Provide?" in Proceedings of the Bicentennial Conference on Bibliographic Control for the New Millennium, Washington, D.C., Nov. 15-17, 2000, ed. Ann M. Sandberg-Fox, 389-413 (Washington, D.C. : Library of Congress, 2001). www.loc.gov/ catdir/bibcontrol/kaplan.html (accessed Nov. 22, 2005).

71. OCLC, FictionFinder. www.oclc.org/research/projects/frbr/ fictionfinder.htm (accessed Mar. 26, 2007); OCLC, Curioser. www.oclc.org/research/projects/curiouser/default.htm (accessed Mar. 26, 2007).

72. Edgar A. Jones, "The FRBR Model as Applied to Continuing Resources," Library Resources \& Technical Services 49, no. 4 (2005): 227-242.

73. Library of Congress, "Bibliographic Control of Web Resources: A Library of Congress Action Plan" (last updated Feb. 23, 2005). www.loc.gov/catdir/bibcontrol/actionplan.pdf (accessed Dec. 1, 2006).

74. Yee, "FRBRization"; Library of Congress, Network Development and MARC Standards Office, Displays for Multiple Versions from MARC 21 and FRBR (Washington, D.C.: Library of Congress, 2003). www.loc.gov/marc/marc-functional -analysis/multiple-versions.html (accessed Aug. 10, 2005).

75. Martha M. Yee, "Lubetzky's Work Principle" in The Future of Cataloging: Insights from the Lubetzky Symposium, Apr. 18, 1998, University of California Los Angeles, ed. Tschera Harkness Connell and Robert L. Maxwell, 72-104 (Chicago: ALA, 2000).

76. International Federation of Library Associations and Institutions UBCIM Working Group on Functional Requirements and Numbering of Authority Records (FRANAR), Functional Requirements for Authority Records [draft 2005/06/15].

77. Bernhard Eversberg, "The Part-Whole Relationship in German and American Cataloging Data: Results and Suggestions," in REUSE+: Joint Project of OCLC and Niedersächsische Staats-und Universitätsbibliothek Göttingen (1998). www .allegro-c.de/formate/reusep.htm (accessed Mar. 26, 2007).

78. Coyle, "Future Considerations," 168.

79. Martha M. Yee, "What Is a Work?" in The Principles and Future of AACR: Proceedings of the International Conference on the Principles and Future Development of AACR, Toronto, Ontario, Canada, October 23-25, 1997, ed. Jean Weihs, 62-104 (Chicago: ALA, 1998).

80. Barbara B. Tillett, “FRBR and Cataloguing Rules: Impact on 
IFLA's Statement of Principles and AACR/RDA," www.oclc .org/research/events/FRBR-workshop/program.htm (accessed June 20, 2005).

81. Ibid.

82. Ibid., 6 .

83. John C. Attig, "Descriptive Cataloging Rules and MachineReadable Record Structures: Some Directions for Parallel Development," in The Conceptual Foundations of Descriptive Cataloging, ed. Elaine Svenonius, 135-148 (San Diego: Academic Press, 1989); Yee; "What is a Work?"

84. Attig, "Descriptive Cataloging Rules and MachineReadable Record Structures: Some Directions for Parallel Development."

85. Ibid

86. Yee, "What is a Work?"; Martha M. Yee, "Editions: Brainstorming for AACR2000," in The Future of the Descriptive Cataloging Rules: Papers from the ALCTS Preconference, AACR2000, American Library Association Annual Conference, Chicago, June 22, 1995, ed. Brian E.C. Schottlaender, 40-65. ALCTS Papers on Library Technical Services and Collections, no. 6 (Chicago: ALA, 1998).

87. Yee, "What is a Work?," 96-97.

88. "RLG to Combine with OCLC," OCLC news release, May 3, 2006. www.oclc.org/news/releases/200618.htm (accessed July 12, 2006); "Endeavor Information Systems to be Merged With Ex Libris," Ex Libris news release, Nov. 21, 2006. www .exlibrisgroup.com/newsdetails.htm?nid=499 (accessed Dec. $22,2006)$.
89. Attig, "Descriptive Cataloging Rules and Machine-Readable Record Structures."

90. Brian E.C. Schottlaender, transcribed by M. Larsgaard, "AACR2 Complexities, Necessary and Otherwise: The Delsey Report, the Cardinal Principle and (ER) Harmonization," in Cataloging the Web: Metadata, AACR and MARC21, ed. Wayne Jones, Judith R. Ahronheim, and Josephine Crawford, 15-19. ALCTS Papers on Library Technical Services and Collections, no. 10 (Lanham, Maryland: Scarecrow Press, 2002).

91. Ibid., 17.

92. International Federation of Library Associations and Institutions, $\operatorname{ISBD}($ ER): International Standard Bibliographic Description for Electronic Resources; IFLA, Functional Requirements for Bibliographic Records: Final Report.

93. International Federation of Library Associations and Institutions, "IFLAnet Web Site." www.ifla.org/VII/s13/index. htm (accessed June 10, 2005).

94. First International Meeting of Experts for an International Cataloguing Code, July 28-30, 2003, Frankfurt am Main, Germany. www.ddb.de/standardisierung/afs/imeicc_index. htm (accessed Mar. 26, 2007).

95. Yee, "FRBRization."

96. Lorcan Dempsey, "The Recombinant Library: Portals and People," Journal of Library Administration 39, no. 4 (2003): 108-109. 